Original Article

\title{
The effects of smartphone use on upper extremity muscle activity and pain threshold
}

\author{
Minkyung LeE ${ }^{1-3)}$, Yunkyung Hong ${ }^{1-3)}$, Seunghoon Lee ${ }^{1-4)}$, Jinyoung Won $^{1-3)}$, Jinjun YanG ${ }^{4}$, \\ Sookyoung Park ${ }^{2)}$, Kyu-Tae $\mathrm{ChanG}^{5}$, $^{*}$, YongGeun Hong ${ }^{1-4)^{*}}$ \\ 1) Department of Rehabilitation Science, Graduate School of Inje University, Republic of Korea \\ 2) Ubiquitous Healthcare Research Center (u-HARC), Inje University, Republic of Korea \\ 3) Biohealth Products Research Center (BPRC), Inje University, Republic of Korea \\ 4) Department of Physical Therapy, College of Biomedical Science and Engineering, Inje University: \\ 197 Inje-ro, Gimhae, Gyeong-nam 621-749, Republic of Korea \\ 5) National Primate Research Center (NPRC), Korea Research Institute of Bioscience and \\ Biotechnology (KRIBB), Republic of Korea
}

\begin{abstract}
Purpose] The purpose of this study was to determine whether muscle activity and pressure-induced pain in the upper extremities are affected by smartphone use, and to compare the effects of phone handling with one hand and with both hands. [Subjects] The study subjects were asymptomatic women 20-22 years of age. [Methods] The subjects sat in a chair with their feet on the floor and the elbow flexed, holding a smartphone positioned on the thigh. Subsequently, the subjects typed the Korean anthem for 3 min, one-handed or with both hands. Each subject repeated the task three times, with a 5-min rest period between tasks to minimize fatigue. Electromyography (EMG) was used to record the muscle activity of the upper trapezius (UT), extensor pollicis longus (EPL), and abductor pollicis (AP) during phone operation. We also used a dolorimeter to measure the pressure-induced pain threshold in the UT. [Results] We observed higher muscle activity in the UT, AP, and EPL in one-handed smartphone use than in its two-handed use. The pressure-induced pain threshold of the UT was lower after use of the smartphone, especially after one-handed use. [Conclusion] Our results show that smartphone operation with one hand caused greater UT pain and induced increased upper extremity muscle activity.

Key words: VDT, Smartphone, Muscle pain
\end{abstract}

(This article was submitted Jan. 14, 2015, and was accepted Mar. 24, 2015)

\section{INTRODUCTION}

A smartphone is a mobile hand-held device with advanced computing capability, such as internet communication, information retrieval, video, e-commerce, and other capabilities. Because of its portability, the smartphone has had a large impact on modern everyday life. Smartphone owners comprise $56 \%$ of American adults, and their average daily use is 195 minutes $^{1,2)}$. The number of users is expected to increase by $22.5 \%$ in 2014 , with 1.75 billion users in Europe alone ${ }^{2)}$.

Smartphone users often complain of a variety of symptoms, such as headache, hand tremor, and finger discomfort $^{3)}$. Berolo et al. reported that mobile hand-held device users complain of discomfort in at least one area of the upper extremities, upper back, or neck ${ }^{4}$. Long-term use of smartphones causes continuous mechanical stress on the

*Corresponding author. Yonggeun Hong and Kyu-Tae Chang (E-mail: yonghong@inje.ac.kr; changkt@kribb.re.kr)

C2015 The Society of Physical Therapy Science. Published by IPEC Inc. This is an open-access article distributed under the terms of the Creative Commons Attribution Non-Commercial No Derivatives (by-ncnd) License $<$ http://creativecommons.org/licenses/by-nc-nd/3.0/>. tendons, muscles, and perimetric tissue, which can induce musculoskeletal symptoms of visual display terminal (VDT) syndrome ${ }^{5,6)}$. Work with VDTs has been reported to cause pain in the neck and shoulders due to increased tension caused by a continuously flexed neck posture ${ }^{7)}$. Several studies have reported severe musculoskeletal problems in workers using desktop computers, which has prompted the recommendation of regular rest periods, stretching, and exercise during performance of computer tasks ${ }^{7-9}$ ).

Although numerous physical problems induced by VDT use have been reported, studies are still lacking that compare two-handed vs. one-handed handling of mobile devices. In the present study, we investigated musculoskeletal changes and pain in the upper extremities of smartphone users operating a smartphone with a single hand and with both hands, providing new data on smartphone-related health problems.

\section{SUBJECTS AND METHODS}

Ten right-handed female subjects volunteered for this study, and all subjects signed an informed consent form. The subjects' mean age was $21 \pm 0.76$ year-old, their mean height was $161.75 \pm 2.05 \mathrm{~cm}$, and their mean body weight was $50.34 \pm 6.50 \mathrm{~kg}$. Exclusion criteria were any limitations in upper extremity movement or a history of upper extremity 
orthopedic problems in the last 6 months. All procedures of this study followed the guideline recommended follow-up protocol of Inje University Faculty of Health Science Human Ethics Committee. Volunteers sat in a chair with their feet on the floor and the elbow flexed, holding a smartphone positioned on the thigh. The subjects typed the Korean anthem for 3 min using either one hand or both hands. Each subject repeated the task three times, with a 5-min rest period between tasks to minimize fatigue. During performance of the task, electromyography (EMG) was employed using a surface Biopac MP150WSW (Biopac Systems, Santa Barbara, CA, USA) to record the muscle activities of the right upper trapezius (UT), extensor pollicis longus (EPL), and abductor pollicis (AP) ${ }^{10)}$. The ground electrode was placed at the seventh cervical vertebra (C7). EMG signals were sampled at $1,000 \mathrm{~Hz}$, and band-pass filtered between 20-450 Hz. The root mean square (RMS) of the signal was calculated, and were normalized to the EMG data maximum voluntary isometric contraction (MVIC) ${ }^{10)}$. A dolorimeter (Fabrication Enterprises, White Plains, NY, USA) was used to measure the tenderness of the UT. All statistical analyses were performed using SPSS software ver. 19.0 (IBM, New York, NY, USA). One-way repeated-measures ANOVA was used to compare the pressure-induced pain thresholds among the baseline value (prior to smartphone use) and the values after one-handed and two-handed use. A non-parametric Wilcoxon test was used to compare muscle activities. Statistical significance was accepted for values of $p<0.05$.

\section{RESULTS}

Muscle activities of the UT, EPL, and AP were significantly higher during single-handed smartphone use than in two-handed smartphone use $(\mathrm{p}<0.05)$ (Table 1). Smartphone use also resulted in increased muscle tenderness in the UT, especially with single-handed use (Table 2).

\section{DISCUSSION}

Kalson reported that $74 \%$ of all mobile hand-held device users observed in an airport most frequently used the device with a single hand ${ }^{11)}$. Few studies have focused on the actual methods of handling mobile devices, although it is known that the physical demands of one-handed use are greater than those of operation with two hands $4,11,15)$. Therefore, the present study compared the muscle activities of the UT, EPL, and AP, and the UT pain threshold when smartphone users handled the device with both hands or with a single hand. Muscle activity of the UT was lower in subjects using the smartphone with both hands (5.84\% MVIC) than that in subjects performing bilateral work using a computer $(6.6-9.0 \% \mathrm{MVIC})^{12)}$. Furthermore, UT activity was higher in the case of computer use with a single dominant hand (11.1\% MVIC) than with both hands, suggesting that the highest muscle load and fatigue occur with one-handed use of mobile devices. The UT is known to operate not only as a mobilizer but also as a stabilizer of the upper extremity. The activities of the AP and EPL, which play key roles in wrist stability $^{13,14)}$, were also higher in one-handed use in our
Table 1. Comparison of normalized muscle activities of one-handed and two-handed smartphone use

\begin{tabular}{ccc}
\hline & \multicolumn{2}{c}{ Mean \pm SD $(\%$ MVIC $)$} \\
\hline Muscles & Both hands $(\mathrm{n}=10)$ & One hand $(\mathrm{n}=10)$ \\
\hline UT & $5.8 \pm 4.0$ & $11.1 \pm 5.3^{*}$ \\
EPL & $12.1 \pm 4.6$ & $21.0 \pm 10.0^{*}$ \\
AP & $23.2 \pm 19.4$ & $50.2 \pm 21.8^{*}$ \\
\hline$* \mathrm{p}<0.05$ & &
\end{tabular}

Table 2. Pressure pain threshold in the UT after smartphone use

\begin{tabular}{lccc}
\hline Pain & Baseline & $\begin{array}{c}\text { Both hands } \\
(\mathrm{n}=10)\end{array}$ & $\begin{array}{c}\text { One hand } \\
(\mathrm{n}=10)\end{array}$ \\
\hline Tenderness & $5.5 \pm 3.3$ & $3.4 \pm 2.5^{*}$ & $2.9 \pm 2.2^{* *}$ \\
\hline${ }^{*} \mathrm{p}<0.05 ;{ }^{* *} \mathrm{p}<0.01$ & &
\end{tabular}

study. Increased AP, EPL, and UT activities may compensate for instability in the shoulder and wrist during single-hand device handling.

VDT use has been reported to significantly decrease the pressure-induced pain threshold ${ }^{15)}$. Berolo et al. reported that mobile hand-held device users complain of discomfort in at least one area of the upper extremities, upper back, or neck ${ }^{4}$. The researchers also reported a significant association between the total time spent using a mobile device each day and pain in the right shoulder, and between the time spent internet browsing and pain at the base of the right thumb ${ }^{4}$. Consistent with the results of Berolo et al., we also observed a lower pain threshold after smartphone use regardless of the handling method. Compared with the baseline, smartphone use significantly increased muscle tenderness in the UT. One-handed use particularly increased pressure-induced pain. The repeated upper extremity movements required by mobile phone use induce continuous muscle contraction in the neck and shoulders, which may result in susceptibility to musculoskeletal disorders because of microscopic damage to the muscles, nerves, and blood vessels during task performance ${ }^{15)}$. The static and asymmetric position adopted during smartphone use may also be a potential risk factor of musculoskeletal disorders ${ }^{6}$. Therefore, we recommend smartphone use with both hands to reduce the risk of musculoskeletal problems.

The limitations of the present study include the small number of the subjects and the brief time spent in smartphone use. Further studies are needed to examine changes in the muscle activity, pain, and biomechanics associated with long-term one-handed smartphone use.

\section{ACKNOWLEDGEMENT}

This work was supported by the KRIBB Research Initiative Program (KGM4611411 to Y.H.), Republic of Korea. S.L. which is supported by the 2014 Post-doctoral Research Program of Inje University. 


\section{REFERENCES}

1) Pew research center: Smartphone Ownership 2013. http://www.pewinter net.org/2013/06/05/ smartphone-ownership-2013 (Accessed Jun. 5, 2013)

2) Lahkola A, Auvinen A, Raitanen J, et al.: Mobile phone use and risk of glioma in 5 North European countries. Int J Cancer, 2007, 120: 1769-1775. [Medline] [CrossRef]

3) Eom SH, Choi SY, Park DH: An empirical study on relationship between symptoms of musculoskeletal disorders and amount of smartphone usage. J Korea Saf Manage, 2013, 15: 113-120. [CrossRef]

4) Berolo S, Wells RP, Amick BC 3rd: Musculoskeletal symptoms among mobile hand-held device users and their relationship to device use: a preliminary study in a Canadian university population. Appl Ergon, 2011, 42 371-378. [Medline] [CrossRef]

5) $\mathrm{Ma} \mathrm{C}, \mathrm{Li} \mathrm{W}$, Cao J, et al.: A Fatigue Detect System Based on Activity Recognition. In: Internet and Distributed Computing Systems; Lecture Notes in Computer Science. Cham: Springer International Publishing, 2014, pp 303-311.

6) Ko K, Kim HS, Woo JH: The study of muscle fatigue and risks of musculoskeletal system disorders from text inputting on smartphone. J Ergo Soc Korea, 2013, 32: 273-278. [CrossRef]

7) Johnston V, Souvlis T, Jimmieson NL, et al.: Associations between individual and workplace risk factors for self-reported neck pain and disability among female office workers. Appl Ergon, 2008, 39: 171-182. [Medline] [CrossRef]

8) Szeto GP, Straker LM, O'Sullivan PB: A comparison of symptomatic and asymptomatic office workers performing monotonous keyboard work-2: neck and shoulder kinematics. Man Ther, 2005, 10: 281-291. [Medline] [CrossRef]

9) Kietrys DM, Galper JS, Verno V: Effects of at-work exercises on computer operators. Work, 2007, 28: 67-75. [Medline]

10) Cram JR, Kasman GS: Holtz J: Introduction to surface electromyography, 1st ed. Maryland: Aspen Publishers, 1998.

11) Karlson AK, Bederson BB, Contreras-Vidal JL: Understanding singlehanded mobile device interaction. HCIL Tech Report, Human-Computer Interaction Lab, University of Maryland, College Park, 2006.

12) Szeto GP, Straker LM, O'Sullivan PB: During computing tasks symptomatic female office workers demonstrate a trend towards higher cervical postural muscle load than asymptomatic office workers: an experimental study. Aust J Physiother, 2009, 55: 257-262. [Medline] [CrossRef]

13) Brand PW, Hollister A: Clinical Mechanics of the Hand, 2nd ed. St Louis: Mosby, 1999.

14) Newmann DA: Kinesiology of the musculoskeletal system; Foundations for physical rehabilitation, 2nd ed. St Louis: Mosby, 2009, pp 131-140.

15) Kim GY, Ahn CS, Jeon HW, et al.: Effects of the use of smartphones on pain and muscle fatigue in the upper extremity. J Phys Ther Sci, 2012, 24: 1255-1258. [CrossRef] 